\title{
Topical azithromycin or ofloxacin for endophthalmitis prophylaxis after intravitreal injection
}

This article was published in the following Dove Press journal:

Clinical Ophthalmology

8 October 2012

Number of times this article has been viewed

\author{
Pedro Romero-Aroca' \\ Laura Sararols ${ }^{2}$ \\ Lluis Arias ${ }^{3}$ \\ Ricardo P Casaroli-Marano ${ }^{4}$ \\ Francisca Bassaganyas ${ }^{5}$ \\ 'Department of Ophthalmology, \\ Hospital Universitari Sant Joan, \\ Universidad Rovira i Virgili, Reus, \\ ${ }^{2}$ Department of Ophthalmology, \\ Hospital de Granollers, Granollers, \\ ${ }^{3}$ Department of Ophthalmology, \\ Hospital Universitari de Bellvitge, \\ Barcelona, ${ }^{4}$ Instituto Clínico de \\ Oftalmologia, Hospital Clínic de \\ Barcelona, Barcelona, ${ }^{5}$ Department of \\ Ophthalmology, Hospital de la Sant \\ Creu i Sant Pau, Barcelona, Spain
}

Correspondence: Pedro Romero-Aroca Department of Ophthalmology, Hospital Universitari Sant Joan, Universidad Rovira i Virgili, Av del Dr Josep Laporte, 243204 Reus, Spain

Tel +34 977310300 ext 5308

Fax +34 977323754

Email romeropere@gmail.com
Background: The number of patients who have undergone intravitreal injections has increased enormously in recent years, but a consensus is still lacking on prophylaxis for endophthalmitis. The aim of this prospective, observational study was to evaluate the prophylactic effect of azithromycin eye drops versus ofloxacin eye drops.

Methods: The study was conducted in five hospitals in Spain and included all patients undergoing intravitreal injections of triamcinolone, bevacizumab, ranibizumab, or pegaptanib over one year. Patients received azithromycin $15 \mathrm{mg} / \mathrm{g}$ eye drops (twice daily on the day prior to injection and for another 2 days) or ofloxacin $3 \mathrm{mg} / \mathrm{g}$ eye drops (every 6 hours on the day prior to injection and for another 7 days).

Results: In the azithromycin group, there were 4045 injections in 972 eyes of 701 patients. In the ofloxacin group, there were 4151 injections in 944 eyes of 682 patients. There were two cases of endophthalmitis $(0.049 \%)$ in the azithromycin group and five $(0.12 \%)$ in the ofloxacin group. The odds ratio of presenting with endophthalmitis in the ofloxacin group compared with the azithromycin group was 2.37 (95\% confidence interval [CI] 1.32-3.72, $P<0.001)$. There were two cases of noninfectious uveitis after triamcinolone injection in the azithromycin group $(0.049 \%)$ and two $(0.048 \%)$ in the ofloxacin group; no significant differences were observed (odds ratio $0.902,95 \%$ CI $0.622-1.407, P=0.407$ ). Conjunctival hyperemia was observed in 12 cases in the azithromycin group and none in the ofloxacin group.

Conclusion: The risk of endophthalmitis was significantly greater with ofloxacin than with azithromycin. These findings provide a valuable addition to the ever-increasing pool of information on endophthalmitis prophylaxis after intravitreal injection, although further large-scale studies are required to provide definitive conclusions.

Keywords: endophthalmitis prophylaxis, intravitreal injections, azithromycin, ofloxacin, antibiotics

\section{Introduction}

The number of patients who have undergone intravitreal injections has increased enormously in recent years, partly due to the greater number of pathologies in which these injections are indicated (diabetic retinopathy, age-related macular degeneration, diabetic or retinal venous occlusion, macular edema, or uveitis) and partly because of the growing number of available drugs that can be administered in this way. ${ }^{1}$ Intravitreal antibiotics were first used at the end of the 1990s and early in the new millennium, and new drugs are constantly being commercialized for intravitreal injection, such as corticosteroids and anti-vascular endothelial growth factor agents. In the coming years, more new drugs will likely become available; slow-release drugs such as fluocinolone 
are already approved in some territories, and intravitreal implants are already under consideration. However, this increase in the number of intravitreal injections has also meant an increase in the number of complications, such as post-intravitreal injection endophthalmitis, over the past few years. ${ }^{2}$

Despite the existence of guidelines ${ }^{3}$ and a degree of conformity in procedures for intravitreal injection, differences between institutions and physicians ${ }^{4}$ have resulted in some variation in the rate of endophthalmitis; however, the most studies report rates in the range of $0.02 \%-0.3 \%{ }^{5-9}$

Prophylaxis for postoperative endophthalmitis after cataract surgery has improved in recent years with the postoperative administration of eye drops (such as fourthgeneration quinolones) or intracameral cephalosporin injection at the end of surgery. ${ }^{10-15}$ Conversely, information is lacking on postoperative endophthalmitis prophylaxis after intravitreal injections. ${ }^{16,17}$ Endophthalmitis is a relatively rare complication of intravitreal injection and so controlled clinical trials require large patient samples to provide definitive conclusions. At present, one approach for prophylaxis consists of instillation of povidone iodine into the conjunctival sac prior to injection, plus subsequent administration of antibiotic eye drops. ${ }^{18}$ The aim of this study was to evaluate the prophylactic effect of azithromycin versus ofloxacin eye drops against endophthalmitis after intravitreal injection.

\section{Materials and methods}

This prospective, observational study was conducted in five hospitals in Spain. The study population included all patients undergoing intravitreal injections of triamcinolone, bevacizumab, ranibizumab, or pegaptanib from January 2010 to December 2010. Patients undergoing ocular surgery or those allergic to quinolones or macrolides were excluded.

\section{Prophylactic treatment}

The prophylactic protocol consisted of topical povidone iodine $10 \%$ on the skin of the periorbital region plus $5 \%$ on the conjunctiva and eyelashes for a minimum of one minute. The periorbital region and eyelashes were draped and a sterile lid speculum, topical anesthetic, and sterile gloves were used. Patients were randomized to receive azithromycin $15 \mathrm{mg} / \mathrm{g}$ eye drops (twice daily on the day prior to injection and for 2 days post-injection) or ofloxacin $3 \mathrm{mg} / \mathrm{g}$ eye drops (every 6 hours on the day prior to injection and for another 7 days).

\section{Standard operation procedures}

After prophylactic measures, the injection was made at the temporal inferior quadrant $4 \mathrm{~mm}$ from the limbus. All patients were examined the day before injection.

\section{Assessments}

A total of eight follow-up visits every 6 weeks were scheduled. A complete ophthalmologic examination was performed at each visit. Vitreous samples were obtained by manual virtrectomy before intravitreal antibiotics in patients showing signs of acute endophthalmitis.

\section{Definition of acute postoperative endophthalmitis}

A diagnosis of presumed acute endophthalmitis was made by the ophthalmologist according to Endophthalmitis Vitrectomy Study criteria. ${ }^{19}$ All suspected cases had swollen eye lids, pain and an opaque vitreous. ${ }^{20}$ If a positive culture of vitreous sample was obtained, the case was confirmed as acute endophthalmitis. The diagnosis of pseudoendophthalmitis secondary to intravitreal triamcinolone injection was based on decreased visual acuity, without pain and with minimal red eye that appeared 1-3 days after the injection, with hyalitis and a fibrinous reaction in the anterior chamber.

\section{Microbiological methods}

Vitreous samples obtained by the ophthalmologist were processed immediately. A Gram stain was performed and the sample cultivated in Petri dishes. Antibiogram susceptibility testing was performed according to MENSURA (Mesa Española de Normalización de la Sensibilidad y Resistencia a los Antimicrobianos) criteria..$^{21,22}$

\section{Statistical analyses}

Statistical analyses were performed using SPSS statistical software version 17.0 (SPSS Inc, Chicago, IL). Values are expressed as the mean \pm standard deviation, and statistical analysis was determined using the Mann-Whitney $U$ test.

\section{Results}

A total of 1383 patients were included. The mean patient age was $69.8 \pm 7.55(53-89)$ years in the azithromycin group and $68.17 \pm 7.83(53-90)$ years in the ofloxacin group $(P=0.372)$. Females accounted for $58 \%$ of patients in both groups. There were no statistically significant differences between the groups. The drugs injected in each group are shown in Table 1. Again, there were no statistically significant differences between the groups. In the azithromycin group, there were a total of 
Table I Intravitreal injections and drugs administered

\begin{tabular}{lll}
\hline & Azithromycin $(\mathbf{n}=\mathbf{4 0 4 5})$ & Ofloxacin $(\mathbf{n}=\mathbf{4}$ I 5 I $)$ \\
\hline Ranibizumab & 2648 & 2946 \\
Bevacizumab & 872 & 840 \\
Pegaptanip & 52 & 42 \\
Triamcinolone & 476 & 323 \\
\hline
\end{tabular}

4045 injections in 972 eyes of 701 patients (4.16 injections per eye and 5.77 injections per patient). In the ofloxacin group, there were a total of 4151 injections in 944 eyes of 682 patients (4.39 injections per eye and 6.08 injections per patient).

\section{Endophthalmitis cases}

There were two cases $(0.049 \%)$ of endophthalmitis (acute endophthalmitis and pseudoendophthalmitis) within a mean time of $4.37 \pm 1.33$ days after surgery in the azithromycin group and five cases $(0.12 \%)$ within a mean time of $4.41 \pm 1.29$ days in the ofloxacin group. The characteristics of the seven cases are shown in Table 2. The risk (odds ratio) of presenting with endophthalmitis in the ofloxacin group compared with the azithromycin group was 2.37 (95\% confidence interval $[\mathrm{CI}] 1.32-3.72, P<0.001)$. When limiting the analysis to culture-positive cases (one case in the azithromycin group and three in the ofloxacin group), the estimated relative risk was $3.01(95 \% \mathrm{CI} 1.97-4.11, P<0.001)$.

\section{Adverse reactions}

There were two cases of uveitis after triamcinolone injection in the azithromycin group $(0.049 \%)$ and two cases $(0.048 \%)$ in the ofloxacin group. No significant differences were observed in the statistical analysis (odds ratio $0.902,95 \%$ CI $0.622-1.407, P=0.407$ ). No cases of raised intraocular pressure were recorded. The characteristics of the patients are shown in Table 3.

Table 2 Characteristics of patients with endophthalmitis

\begin{tabular}{|c|c|c|c|c|}
\hline Gender & Age & $\begin{array}{l}\text { Drug } \\
\text { injected }\end{array}$ & Culture & $\begin{array}{l}\text { Endophthalmitis } \\
\text { treatment }\end{array}$ \\
\hline \multicolumn{5}{|c|}{ Azithromycin $(n=2)$} \\
\hline Male & 77 & Ranibizumab & S. epidermidis & Intravitreal antibiotics \\
\hline Female & 80 & Pegaptanip & Negative & Intravitreal antibiotics \\
\hline \multicolumn{5}{|c|}{ Ofloxacin $(n=5)$} \\
\hline Male & 76 & Ranibizumab & S. epidermidis & Intravitreal antibiotics \\
\hline Male & 72 & Ranibizumab & S. epidermidis & $\begin{array}{l}\text { Intravitreal antibiotics + } \\
25 \text {-gauge vitrectomy }\end{array}$ \\
\hline Female & 77 & Ranibizumab & S. aureus & Intravitreal antibiotics \\
\hline Female & 69 & Ranibizumab & Negative & Intravitreal antibiotics \\
\hline Male & 76 & Ranibizumab & Negative & Intravitreal antibiotics \\
\hline
\end{tabular}

Abbreviations: S. epidermidis, Staphylococcus epidermidis; S. aureus, Staphylococcus aureus.
Table 3 Characteristics of patients with triamcinolone reaction

\begin{tabular}{lcll}
\hline Gender & Age & Culture & Ocular pathology \\
\hline \multicolumn{2}{l}{ Azithromycin $(\mathbf{n}=\mathbf{2})$} & & \\
Male & 78 & Negative & Diabetic macular edema \\
Female & 82 & Negative & Diabetic macular edema \\
Ofloxacin $(\mathbf{n}=\mathbf{2})$ & & \\
Female & 71 & Negative & Diabetic macular edema \\
Female & 74 & Negative & Diabetic macular edema \\
\hline
\end{tabular}

Other complications included conjunctival hyperemia (12 cases with azithromycin [0.29\%] and none with ofloxacin), punctate keratitis (two cases with azithromycin and none with ofloxacin), subconjunctival hemorrhage (eight cases with azithromycin and six with ofloxacin) and a decrease in acute visual acuity with relapse a few minutes after intravitreal injection (three cases in each group).

\section{Discussion}

With the considerable growth in the use of intravitreal injections in recent years, there has been an increasing interest in determining an effective strategy for endophthalmitis prophylaxis.

The incidence of endophthalmitis, which is a potentially vision-threatening condition, is currently unclear because very few studies have been conducted. Most data are derived from extended clinical trials that attempted to administer drugs intravitreally, such as the RESTORE (Ranibizumab Monotherapy or Combined with Laser versus Laser Monotherapy for Diabetic Macular Edema) study, in which no endophthalmitis cases were observed after 2415 injections ${ }^{23}$ or the Diabetic Retinopathy Clinical Research Network ${ }^{24}$ study in which one patient $(0.9 \%$; $95 \%$ CI 0.02-4.7) developed endophthalmitis after receiving ranibizumab. According to the meta-analysis by Jager et al, ${ }^{18}$ the incidence of endophthalmitis after use of intravitreal medicines is $0.3 \%$ per injection and $0.9 \%$ per eye. The Vitravene Study Group ${ }^{25}$ described two cases of endophthalmitis after 1791 injections $(0.11 \%)$ in 330 eyes $(0.60 \%)$.

A larger study was performed by McCannel et $\mathrm{al}^{26}$ who conducted a meta-analysis of the US literature from 2005 to 2009 and observed a total of 52 cases of endophthalmitis in 105,536 injections, with an incidence of $0.049 \%$ (95\% CI 0.038-0.065). In this study, endophthalmitis culture was negative in 24 cases $(48.0 \%$ [ $95 \%$ CI 34.8-61.5]) and positive in 26 (52\% [95\% CI 38.5-65.2]). Of the 26 culture-positive isolates, the causative organisms were coagulase-negative Staphylococcus spp. in 17 cases $(65.4 \%$ [95\% CI 46.0-80.6]), Streptococcus spp. in eight cases 
(30.8\% [95\% CI 16.5-50.2]), and Bacillus cereus in one case (3.8\% [95\% CI 0.9-19.0]). The authors found a significantly higher number of cases due to Streptococcus species than after cataract surgery in the Endophthalmitis Vitrectomy Study. The percentage of cases with endophthalmitis in the current study was similar to that in the published data, at $0.049 \%$ in the azithromycin group and $0.12 \%$ in the ofloxacin group. Unlike McCannel et al, ${ }^{26}$ the most commonly found bacterium (three of the four positive cases) in our study was Staphylococcus epidermidis.

Because little is known about the incidence of endophthalmitis, it is unclear whether prophylactic antibiotics should be used. Some authors, such as Bhatt et al, ${ }^{27}$ concluded that "the rate of endophthalmitis after intravitreal injections administered in a clinical practice setting when aseptic technique is used is similar with or without the use of post injection antibiotics", but their study was based on a small number of patients. In contrast, most scientific bodies recommend the use of topical antibiotics in addition to prophylactic measures during surgery such as povidone iodine instillation on the conjunctiva, draping of the periorbital region and eyelashes, and the use of a sterile lid speculum. However, there are few recommendations on antibiotic use. The Royal College of Ophthalmologists ${ }^{28}$ recommends a dose of antibiotics before injecting the drug, while the Spanish Society of Retina and Vitreous recommends topical antibiotic treatment after injection. ${ }^{29}$ The French Agence Nationale de Sécurité du Médicament also recently recommended topical antibiotics after injection, but stated that systemic administration is not indicated. ${ }^{30}$ They advised referring to the marketing authority for the substance being injected for advice on preinjection topical antibiotic prophylaxis.

Azithromycin was chosen for this study because it is a broad spectrum antibiotic that covers most commonly found bacteria in the environment and is more potent against most Gram-negative organisms than erythromycin. ${ }^{31,32}$ Furthermore, adequate and long-lasting levels were observed in the conjunctiva that remained well above the minimum inhibitory concentration (MIC) breakpoint for susceptible organisms for up to 24 hours after instillation. Residual azithromycin levels observed 7 days after the last administration were above the MIC breakpoint of $0.5 \mu \mathrm{g} / \mathrm{g}$ in the conjunctiva and cornea. This permits topical administration twice daily for 3 days, resulting in significant concentrations in the conjunctiva and cornea for at least 7 days after final administration. ${ }^{33,34}$ Although azithromycin has poor intraocular penetration when given topically, its main role is via the elimination of periocular bacteria.
In the current study, we observed that the number of endophthalmitis cases was higher in the group that used ofloxacin $(0.12 \%)$ versus the azithromycin group $(0.049 \%)$, resulting in a significantly increased risk of endophthalmitis of 2.37 ( $P<0.001)$. However, the relatively low sample size and incidence of endophthalmitis is one of the major limitations of the study that precludes any categorical confirmation of the advantage of one drug over the other in the prophylaxis of endophthalmitis after intravitreal injection. Azithromycintreated patients had a somewhat higher rate of conjunctival hyperemia, that was nevertheless seen in less than three cases per 1000. There were no differences in other adverse events.

In conclusion, these findings provide a valuable addition to the ever-increasing pool of information on endophthalmitis prophylaxis after intravitreal injection, although further similar large-scale studies will be required before reaching definitive conclusions.

\section{Acknowledgment}

Editorial support was provided by Jane Irons.

\section{Disclosure}

The authors report no conflicts of interest in this work.

\section{References}

1. Prasad AG, Schaudlu R, Apte RS. Intravitreal pharmacotherapy: applications in retinal disease. Compr Ophthalmol Update. 2007;8(5): 259-269.

2. Irigoyen C, Ziahosseini K, Morphis G, Stappler T, Heimann H. Endophthalmitis following intravitreal injections. Graefes Arch Clin Exp Ophthalmol. 2012;250(4):499-505.

3. Bodaghi B, Korobelnik JF, Cochereau I, Hajjar J, Goebel F, Dumarcet N; AFSSAPS (Association Francaise de Securite Sanitaire des Produits de Sante). Intravitreal injections: AFSSAPS guide to good practice. J Fr Ophtalmol. 2012;35(1):69-71. French.

4. Waisbourd M, Goldstein M, Loewenstein A. National survey of the ophthalmic use of anti-vascular endothelial growth factor drugs in Israel. Isr Med Assoc J. 2011;13(3):141-146.

5. Simunovic MP, Rush RB, Hunyor AP, Chang AA. Endophthalmitis following intravitreal injection versus endophthalmitis following cataract surgery: clinical features, causative organisms and post-treatment outcomes. Br J Ophthalmol. 2012;96(6):862-866.

6. Bhavsar AR, Stockdale CR, Ferris FL, Brucker AJ, Bressler NM, Glassman AR; Diabetic Retinopathy Clinical Research Network FT. Update on risk of endophthalmitis after intravitreal drug injections and potential impact of elimination of topical antibiotics. Arch Ophthalmol. 2012;130(6):809-810

7. Angulo Bocco MC, Glacet-Bernard A, Zourdani A, Coscas G, Soubrane G. Intravitreous injection: retrospective study on 2028 injections and their side effects. J Fr Ophtalmol. 2008;31(7):693-698. French.

8. Cheung CS, Wong AW, Lui A, Kertes PJ, Devenyi RG, Lam WC. Incidence of endophthalmitis and use of antibiotic prophylaxis after intravitreal injections. Ophthalmology. 2012;119(8):1609-1614.

9. Moshfeghi AA, Rosenfeld PJ, Flynn HW Jr, et al. Endophthalmitis after intravitreal anti-vascular endothelial growth factor antagonists: a six-year experience at a university referral center. Retina. 2011;31(4): $662-668$. 
10. Jensen MK, Fiscella RG, Moshirfar M, Mooney B. Third- and fourthgeneration fluoroquinolones: retrospective comparison of endophthalmitis after cataract surgery performed over 10 years. J Cataract Refract Surg. 2008;34(9):1460-1467.

11. O’Brien TP, Arshinoff SA, Mah FS. Perspectives on antibiotics for postoperative endophthalmitis prophylaxis: potential role of moxifloxacin. J Cataract Refract Surg. 2007;33(10):1790-1800.

12. Wejde G, Montan P, Lundström M, Stenevi U, Thorburn W. Endophthalmitis following cataract surgery in Sweden: national prospective survey 1999-2001. Acta Ophthalmol Scand. 2005;83(1): $7-10$.

13. Seal DV, Barry P, Gettinby G, et al. ESCRS study of prophylaxis of postoperative endophthalmitis after cataract surgery: case for a European multicenter study. J Cataract Refract Surg. 2006;32(3): 396-406.

14. Garat M, Moser CL, Martín-Baranera M, Alonso-Tarrés C, AlvarezRubio L. Prophylactic intracameral cefazolin after cataract surgery: endophthalmitis risk reduction and safety results in a 6-year study. J Cataract Refract Surg. 2009;35(4):637-642.

15. Romero P, Méndez I, Salvat M, Fernández J, Almena M. Intracameral cefazolin as prophylaxis against endophthalmitis in cataract surgery. J Cataract Refract Surg. 2006;32(3):438-441.

16. Scott IU, Flynn HW Jr. Reducing the risk of endophthalmitis following intravitreal injections. Retina. 2007;27(1):10-12.

17. Bhavsar AR, Googe JM Jr, Stockdale CR, et al. Risk of endophthalmitis after intravitreal injection when topical antibiotics are not required. Arch Ophthalmol. 2009;127(12):1581-1583.

18. Jager RD, Aiello LP, Patel SC, Cunningham ET Jr. Risks of intravitreous injection: a comprehensive review. Retina. 2004;24(5):676-698

19. Endophthalmitis Vitrectomy Study Group. Results of the Endophthalmitis Vitrectomy Study. A randomized trial of immediate vitrectomy and of intravenous antibiotics for the treatment of postoperative bacterial endophthalmitis. Arch Ophthalmol. 1995;113(12):1479-1496.

20. Barry P, Gardner S, Seal D, et al. Clinical observations associated with proven and unproven cases in the ESCRS study of prophylaxis of postoperative endophthalmitis after cataract surgery. J Cataract Refract Surg. 2009;35(9):1523-1531.

21. Baquero F, Martínez-Beltrán J, Cantón R. Criteria of the MENSURA group for the definition of the critical points of sensitivity to antibiotics. Enferm Infecc Microbiol Clin. 1998;16(2):85-92. Spanish.

22. National Committee for Clinical Laboratory Standards. Performance Standards for Antimicrobial Disk Susceptibility Tests: Approved Standard. NCCLS document M2-A7. 7th ed. Wayne, PA: National Committee for Clinical Laboratory Standards; 2002.
23. Mitchell P, Bandello F, Schmidt-Erfurth U, et al. The RESTORE study: ranibizumab monotherapy or combined with laser versus laser monotherapy for diabetic macular edema. Ophthalmology. 2011;118(4):615-625.

24. Bhavsar AR, Ip MS, Glassman AR; DRCRnet and the SCORE Study Groups. The risk of endophthalmitis following intravitreal triamcinolone injection in the DRCRnet and SCORE clinical trials. Am J Ophthalmol. 2007;144(3):454-456

25. Vitravene Study Group. Safety of intravitreous fomivirsen for treatment of cytomegalovirus retinitis in patients with AIDS. Am J Ophthalmol. 2002;133(4):484-498

26. McCannel CA. Meta-analysis of endophthalmitis after intravitreal injection of anti-vascular endothelial growth factor agents: causative organisms and possible prevention strategies. Retina. 2011;31(4):654-661.

27. Bhatt SS, Stepien KE, Joshi K. Prophylactic antibiotic use after intravitreal injection: effect on endophthalmitis rate. Retina. 2011;31(10) 2032-2036.

28. Royal College of Ophthalmologists. Guidelines for Intravitreal Injections Procedure. London, UK: Royal College of Ophthalmologists, 2009. Available from: http://www.rcophth.ac.uk. Accessed August 28, 2012.

29. Sociedad Española de Retina y Vítreo. Manejo de las inyecciones intravítreas. [Management of intravitreal injections]. Guías de Práctica Clínica de la SERV. 2009. Available from: http://www.serv.es. Accessed August 28, 2012. Spanish.

30. Agence Français de Sécurité Sanitaire des Produits de Santé. Bonnes pratiques d'injection intra-vitréenn. [Good practice for intravitreal injection]. 2011. Available from: http://www.ansm.fr. Accessed August 28, 2012. French.

31. Retsema J, Girard A, Schelkly W, et al. Spectrum and mode of action of azithromycin (CP-62,993), a new 15-membered-ring macrolide with improved potency against Gram-negative organisms. Antimicrob Agents Chemother. 1987;31(12):1939-1947.

32. Peters DH, Friedel HA, McTavish D. Azithromycin. A review of its antimicrobial activity, pharmacokinetic properties and clinical efficacy. Drugs. 1992;44(5):750-799.

33. Chiambaretta F, Garraffo R, Elena PP, et al. Tear concentrations of azithromycin following topical administration of a single dose of azithromycin $0.5 \%, 1.0 \%$, and $1.5 \%$ eye drops (T1225) in healthy volunteers. Eur J Ophthalmol. 2008;18(1):13-20.

34. Cochereau I, Meddeb-Ouertani A, Khairallah M, et al. 3-day treatment with azithromycin $1.5 \%$ eye drops versus 7 -day treatment with tobramycin $0.3 \%$ for purulent bacterial conjunctivitis: multicentre, randomised and controlled trial in adults and children. Br J Ophthalmol. 2007;91(4):465-469.
Clinical Ophthalmology

\section{Publish your work in this journal}

Clinical Ophthalmology is an international, peer-reviewed journal covering all subspecialties within ophthalmology. Key topics include: Optometry; Visual science; Pharmacology and drug therapy in eye diseases; Basic Sciences; Primary and Secondary eye care; Patient Safety and Quality of Care Improvements. This journal is indexed on

\section{Dovepress}

PubMed Central and CAS, and is the official journal of The Society of Clinical Ophthalmology (SCO). The manuscript management system is completely online and includes a very quick and fair peer-review system, which is all easy to use. Visit http://www.dovepress.com/ testimonials.php to read real quotes from published authors. 